\title{
PRODUTIVIDADE E RESISTÊNCIA À FERRUGEM DO CAFEEIRO (Hemileia vastatrix BERK. ET BR.) DE PROGÊNIES F5 DE CATUAÍ AMARELO COM O HÍBRIDO DE TIMOR
}

\author{
Produtivity and resistance to "Coffee Rust" (Hemileia vastatrix Berk. Et Br.) of f5 \\ progenies of catuaí amarelo with the híbrido de timor
}

\section{RESUMO}

\author{
José Messias Miranda ${ }^{1}$, Dilermando Perecin², Antonio Alves Pereira ${ }^{3}$
}

Foram estudadas 18 progênies na geração F5 do híbrido H 419, provenientes do cruzamento entre o Híbrido de Timor (UFV 445-46) e o Catuaí Amarelo IAC 30 (UFV 2143), 5 progênies na geração F5 do híbrido H 516, proveniente do cruzamento entre o Híbrido de Timor (UFV 446-08) e o Catuaí Amarelo IAC 86 (UFV 2154) e como controle o Catuaí Vermelho IAC 44 ( UFV 2144 ) com e sem controle da ferrugem. Em relação a produção de café cereja por planta e ao ataque da ferrugem as progênies H419-3-1-1-14 e a H516-2-1-1-18, foram as que apresentaram maiores produtividades e resistência a ferrugem (nota 1 ), seguidas da H419-6-3-612 , porém com resistência parcial à ferrugem. Essas progênies também foram as que apresentaram maior comprimento do ramo plagiotrópico, que influenciou em $37,73 \%\left(\mathrm{R}^{2}\right)$ na produção de café cereja por planta. O comprimento do ramo plagiotrópico, diâmetro do tronco e altura das plantas foram os atributos que mais correlacionaram $\mathrm{r}=0.5977, \mathrm{r}=0.3316 \mathrm{e} \mathrm{r}=0.2848$, respectivamente $\mathrm{p}<0.01$, com as produtividades dessas progênies, concordando com resultados obtidos por Dhaliwal (1968). Em relação a resistência ao fungo Hemileia vastatrix Berk. et Br., as progênies apresentaram herdabilidade no sentido amplo elevada $\left(\mathrm{h}^{2}=0,80\right.$ entre e $h_{a}^{2}=0,96$ entre e dentro das progênies), mostrando variabilidade genética alta para seleção de material resistentes à ferrugem do cafeeiro.

Termos para indexação: Café, resistência, ferrugem, seleção.

\begin{abstract}
Eighteen progenies in the F5 generation of the $\mathrm{H} 419$ hybrid were studied, proceeding from the crossing between the Híbrido deTimor (UFV 445-46) and the IAC 30 Catuaí Amarelo (UFV 2143), 5 progenies in the F5 generation of the H 516 hybrid, proceeding from the crossing between the Híbrido deTimor (UFV 446-08) and the IAC 86 Catuaí Amarelo (UFV 2154) and the IAC 44 the red Catuaí (UFV 2144) as control, with and without rust control. Regarding the production of cherry coffee by plant and with the rust attack, the H419-3-1-1-14 and the H516-2-1-1-18, progenies were the ones that showed greater productivity and rust resistance (grade 0), followed by the H419-6-3-6-12, but with partial rust resistance. These progenies were, also, the ones that showed greater length of the plagiotrophycal spreads, where influenciated in $37.73 \%\left(\mathrm{R}^{2}\right)$ at production of cherry coffee by plant. The plagiotrophycal spread's length, fust diameter and plants height were the most correlated attributes $\mathrm{r}=0.5977, \mathrm{r}=0.3316$ and $\mathrm{r}=0.2848, \mathrm{p}<0.01$ respectively, with these progenies productivity, according results obtained by Dhaliwal (1968). Regarding to the Hemileia vastatrix Berk. et Br. fungus resistance, the progenies showed herdability on the wide-high way $\left(\mathrm{h}_{\mathrm{a}}^{2}=0,80\right.$ between and $\mathrm{h}_{\mathrm{a}}^{2}=0,96$ between and inside the progenies), pointing them as resistant and with a high genetic variability for selection of resistant material to the coffee rust.
\end{abstract}

Index terms: Coffee, resistance, rust, selection.

(Recebido para publicação em 23 de outubro de 2003 e aprovado em 28 de julho de 2005)

\section{INTRODUÇÃO}

No ano de 1970 foi constado a presença do ataque da ferrugem do cafeeiro em todas as regiões cafeeiras do Brasil. Nesta data, a Universidade Federal de Viçosa (UFV), introduziu germoplasmas constituídos por materiais portadores de alelos que conferem a resistência ao agente causador da ferrugem do cafeeiro (Hemileia vastatrix). Este material, oriundo de seleções realizadas pelo Centro de Investigação da Ferrugem do Cafeeiro (CIFC) em
Portugal, Instituto Interamericano de Ciências Agrárias (IICA), na Costa Rica e pelo Centro Nacional de Investigação do Café (CENICAFE), na Colômbia, foi inicialmente plantado em Viçosa-MG, onde foram realizadas as primeiras avaliações e seleção, num trabalho desenvolvido conjuntamente pelas instituições que integram o Sistema de Pesquisas Agropecuária em Minas Gerais: Empresa de Pesquisas Agropecuária de Minas Gerais - EPAMIG, Universidade Federal de Lavras -UFLA e Universidade Federal de Viçosa - UFV.

'Engenheiro Agrônomo, MSc., Doutorando/UNESP - Jaboticabal, SP - messiasmiranda@uol.com.br

Engenheiro Agrônomo, Dr., Professor/UNESP - Jaboticabal, SP - perecin@fcav.unesp.com.br.

${ }^{3}$ Engenheiro Agrônomo, Dr., Pesquisador da EPAMIG - Viçosa, MG - pereira@epamig.ufv.br 
As progênies selecionadas destas introduções foram denominadas de Catimor (Caturra Vermelho X Híbrido de Timor) ; Sarchimor (Vila Sarchi X Híbrido de Timor) ; Cachimor (Catuaí Vermelho e Catuaí Amarelo X Catimor); Catindú (Caturra X seleção Indiana).

Pereira (1995), identificando a herança da resistência à Hemileia vastatrix em cafeeiros derivados do Híbrido de Timor, utilizou cruzamentos com o Catuaí e ou Mundo Novo e, as plantas obtidas apresentaram excelentes características agronômicas.

Sera (1987) afirma que a característica vegetativa que mais frequientemente apresenta associação com a produção é o porte da planta, expresso pela altura e diâmetro de copa.

Dhaliwal (1968) encontrou correlações entre a produção e diversos caracteres em amostras de vários cultivares: $r=0,20(\mathrm{p}<0,05)$ para o diâmetro do tronco; $r$ $=0,16 \mathrm{~ns}$ para o comprimento do ramo plagiotrópico mais comprido e $r=0,08$ n.s a $0,50(p<0,01)$ para o número de internódios dos ramos plagiotrópico primário mais longo.

Vossen (1985) obteve estimativas da $\mathrm{h}_{\mathrm{a}}{ }^{2}$ (herdabilidade no sentido amplo), tanto para a média das progênies, como para as plantas individuais, para dezesseis cultivares avaliadas por dez anos de colheitas em cinco repetições e oito plantas por parcela. Para o primeiro ano de colheita foi estimada $h_{a}^{2}=0,45$ ao nível de progênies e $\mathrm{h}_{\mathrm{a}}{ }^{2}=0,17$ ao nível de plantas individuais. Quando estimadas para os biênios, cumulativamente, a $\mathrm{h}_{\mathrm{a}}{ }^{2}$ variou de 0,72 para o primeiro biênio e 0,81 para os cinco primeiros biênios ao nível de progênies. $\mathrm{O} \mathrm{h}^{2}$ aumenta com o aumento do número de anos de colheitas, pois diminuem progressivamente os efeitos ambientais provocados pelos anos.

Quando se usam gerações iniciais, a ênfase na seleção deve ser dada para a seleção tanto entre como dentro das progênies. Castillo-Zapata \& Moreno-Ruiz (1981) utilizando vinte progênies F3 do cruzamento, Caturra x Híbrido de Timor, observadas na Colômbia durante quatro anos de colheitas, em duas repetições e parcelas de oito plantas estimaram $\mathrm{h}_{\mathrm{a}}{ }^{2}=0,21$ quando se pratica a seleção entre as progênies e $h_{a}^{2}=0,67$ quando se pratica a seleção entre e dentro das progênies.

Mediante a seleção das progênies resultantes desses cruzamentos, objetivou-se com presente trabalho avaliar as progênies F5 oriundas da variedade Catuaí Amarelo com o Híbrido do Timor, selecioná-las para produtividade e resistência à ferrugem (Hemileia vastatrix).

\section{MATERIAL E MÉTODOS}

$\mathrm{O}$ ambiente onde o experimento foi instalado e conduzido corresponde a um solo latotossolo vermelho escuro, com textura moderadamente argilosa, declividade em torno de $17 \%$, temperatura média anual de $18^{\circ}$ a $20^{\circ} \mathrm{C}$ e com precipitação pluviométrica média anual de 1500 a $1700 \mathrm{~mm}$. O local situa-se na Fazenda Experimental da EPAMIG, município de Machado, no sul de Minas Gerais. O ensaio foi iniciado em 17 de agosto de 1998 no viveiro de mudas da Fazenda Experimental da EPAMIG de Machado - MG e montado no campo no dia 10 de fevereiro de 1999.

As progênies de cafeeiro utilizadas são provenientes de hibridações realizadas no Departamento de Fitopatologia da UFV e nas Fazendas Experimentais da EPAMIG. Foram estudadas 18 progênies na geração F5 descendentes do híbrido $\mathrm{H} 419$, proveniente do cuzamento entre o Híbrido de Timor ( UFV 2143 ) e o Catuaí Amarelo IAC 30 ( UFV 445-46) , 5 progênies na geração F5 descendentes do híbrido H 516, proveniente do cruzamento entre o Híbrido de Timor ( UFV 2154 ) e o Catuaí Amarelo IAC 86 ( UFV 446-08 ) e como testemunha o Catuaí Vermelho IAC 44 ( UFV 2144 ) sem e com controle da ferrugem.

O controle da ferrugem do cafeeiro foi realizado apenas na variedade Catuaí por meio de quatro aplicações de oxicloreto de cobre, dois quilogramas por hectare, via foliar, nos meses de outubro, dezembro, fevereiro e abril.

O delineamento experimental utilizado foi o de lattice 5 x 5, com três repetições e cada parcela composta de cinco plantas espaçadas de 1,0 metro entre plantas e de 2,5 metros entre fileiras.

Avaliou-se a produção média, por parcela, de café cereja (frutos em plena maturação), tomando-se a soma das produções das três primeiras colheitas (2001, $2002 \mathrm{e}$ 2003). Também avaliou-se, nos meses de março e agosto, os parâmetros fenotípicos, tais como: altura da planta em metros; diâmetro da base da copa em metros; crescimento dos ramos plagiotrópicos, através do comprimento dos ramos, em centímetros; número de internódios; diâmetro do caule, em centímetros, a 10 centímetros do solo; produção de café cereja, em quilos por planta e incidência de ferrugem, Hemileia vastatrix, notas de 1 a 8 , sendo 1 para as mais resistentes e 8 para as mais susceptíveis.

Para transformar o peso de café cereja por planta para peso em quilos por metro cúbico, tomou-se como base o diâmetro de copa e a altura das plantas. A fórmula utilizada foi: Volume da copa = diâmetro da copa ao quadrado multiplicado por 3.14, dividido por quatro, multiplicado pela altura das plantas e o resultado

Ciênc. agrotec., Lavras, v. 29, n. 6, p. 1195-1200, nov./dez., 2005 
dividido por dois. O volume de café cereja por metro cúbico de copa, foi obtido pela divisão do peso em quilos de café cereja por planta pelo volume de copa calculado acima.

Para análise dos dados foram realizadas análises como blocos casualizados, testes de classificação de médias (Tukey), correlação e regressão dos parâmetros fenotípicos avaliados e a produção média de café cereja por planta e por volume cúbico de copa.

Para a determinação da herdabilidade no sentido amplo entre e dentro das progênies, baseou-se na esperança do quadrado médio na análise de variância, utilizando a produção por plantas individuais. Para o cálcudo da herdabilidade utilizou-se a fórmula, proposta por Vencosvsky \& Barriga (1992), em que a $\mathrm{s}_{\mathrm{p}}{ }^{2}$ variância das progênies é dividida por $\left(\mathrm{s}_{\mathrm{p}}{ }^{2}+\mathrm{s}_{\mathrm{e}}{ }^{2} / \mathrm{r}+\mathrm{s}_{\mathrm{d}}{ }^{2} / \mathrm{nr}\right)$, sendo $\mathrm{s}_{\mathrm{e}}{ }^{2}$ a variância ambiente, $\mathrm{s}_{\mathrm{d}}{ }^{2}$ a variância dentro das progênies, 'n' o número de plantas por progênie e ' $r$ ' o número de repetições.

\section{RESULTADOS E DISCUSSÃO}

Os resultados dos atributos, altura e o diâmetro de copa, são apresentados no Gráfico 1. Observa-se uma correlacão positiva entre eles, $r=0,4137$, significando que as plantas de maior altura são também as de maior diâmetro de copa, como a progênie H516-21-6-13, seguidas das progênies H419-6-1-3-18, H419-31-1-3 e a H516-2-1-1-18. As progênies que apresentaram menor altura e diâmetro de copa foram a H419-10-6-2-9 e a H419-3-3-2-16.

O comprimento do ramo plagiotrópico maior também correlacionou-se positivamente com o número de internódios, $\mathrm{r}=0,3734 \mathrm{e}$ o diâmetro do tronco, $\mathrm{r}=0,5558$. No Gráfico 2, verifica-se que a progênie H516-2-1-6-13 como a que apresentou o maior valor, seguida das progênies H419-6-1-3-18 e da H419-5-3-3-18. Quanto aquelas que apresentaram menores comprimento de ramos destaca-se a H419-10-6-2-9 e a H419-5-1-2-8.

Em relação à produção de café cereja por planta e à incidência da ferrugem (Gráfico 3), a progênie H419-3-1-114 ( 4,54 kg/planta ), porém, suscetível e a H516-2-1-1-18 $(4,21 \mathrm{~kg} /$ planta ), produtiva e resistência à ferrugem ( nota 1 ), seguida da H419-6-3-6-12, porém com resistência parcial à ferrugem (nota 2,06). Essas progênies também estavam entre as que apresentaram maior comprimento do ramo plagiotrópico, o que influenciou em $35,73 \%$ na obtenção dos resultados acima. O comprimento do ramo plagiotrópico, diâmetro do tronco e altura das plantas foram os atributos que mais correlacionaram, $\mathrm{r}=0.5977, \mathrm{r}=0.3316$ e $r=0.2848$, respectivamente $\mathrm{p}<0.01$, com a produtividade dessas progênies, concordando com os resultados obtidos por Dhaliwal (1968). Em relação à progênie UFV 2144 Catuaí, amplamente cultivada no nosso parque cafeeiro, a diferença com a progênie mais produtiva foi de 0,99 quilos de café cereja por planta como também apresentou resistência à ferrugem do cafeeiro.

Quanto à produção de café cereja em quilos por metro cúbico de copa (Gráfico 4) as progênies H419-6-3-612 (4,70 kg/m $\mathrm{m}^{3}$ de copa), H419-3-1-1-14 (4,34 kg/m de copa) e a H419-5-2-1-14 (3,80 kg/m3 de copa), estavam entre as que apresentaram maiores densidades de produção, porém com resistência parcial à ferrugem (notas 2 a 3 ). Destaque também para a progênie H516-2-1-1-18, com alta produtividade e resistência total à ferrugem ( nota 1 ). As progênies citadas foram as que apresentaram diâmetro de copa e comprimento do ramo plagiotrópico maiores, influenciando $16,48 \%$ e $15,58 \%$, respectivamente, nos resultados da produção. O comprimento do ramo plagiotrópico foi o atributo que teve maior coeficiente de correlação, $r=0,3946 \mathrm{p}<0.01$ e o diâmetro de copa $\mathrm{r}=$ $0.1738 p<0.01$, significando que menores diâmetros obtém maiores produtividades por volume de copa. Essas progênies apresentaram uma diferença de $1,21 \mathrm{~kg} / \mathrm{m}^{3}$ de copa em relação à média geral do ensaio e de $1,27 \mathrm{~kg} / \mathrm{m}^{3}$ de copa em relação à progênie UFV 2144 - Catuaí $\left(3,43 \mathrm{~kg} / \mathrm{m}^{3}\right.$ de copa).

As herdabilidades obtidas são apresentadas na Tabela 1. Observa-se que a resistência à ferrugem apresentou uma herdabilidade no sentido amplo alta, $\mathrm{h}_{\mathrm{a}}{ }^{2}$ $=0,80$ entre e de $h_{a}^{2}=0,96$ entre e dentro das progênies, significando que há uma alta variabilidade e que as progênies resistentes possuem geneticamente, com alta confiabilidade, genes que conferem a resistência à ferrugem alaranjada do cafeeiro, Hemileia vastatrix.

Quanto à produção de quilos de café cereja por planta, a herdabilidade obtida entre foi de $h_{a}^{2}=0,16$ entre e de $h_{a}^{2}=0,54$ entre e dentro das progênies. Estes resultados estão de acordo com Castillo-Zapata \& MorenoRuiz (1981) que, obtiveram $h_{a}^{2}=0,21$ entre e de $h_{a}^{2}=0,61$ entre e dentro das progênies.

Pode-se verificar que, em relação à resistência ao fungo Hemileia vastatrix, as progênies F5 pertencentes do cruzamento de Catuaí Amarelo com o Híbrido de Timor, apresentaram herdabilidade no sentido amplo elevado, indicando-as como resistentes e com uma variabilidade genética alta para seleção de materiais resistentes ao ataque do fungo Hemileia vastatrix. 


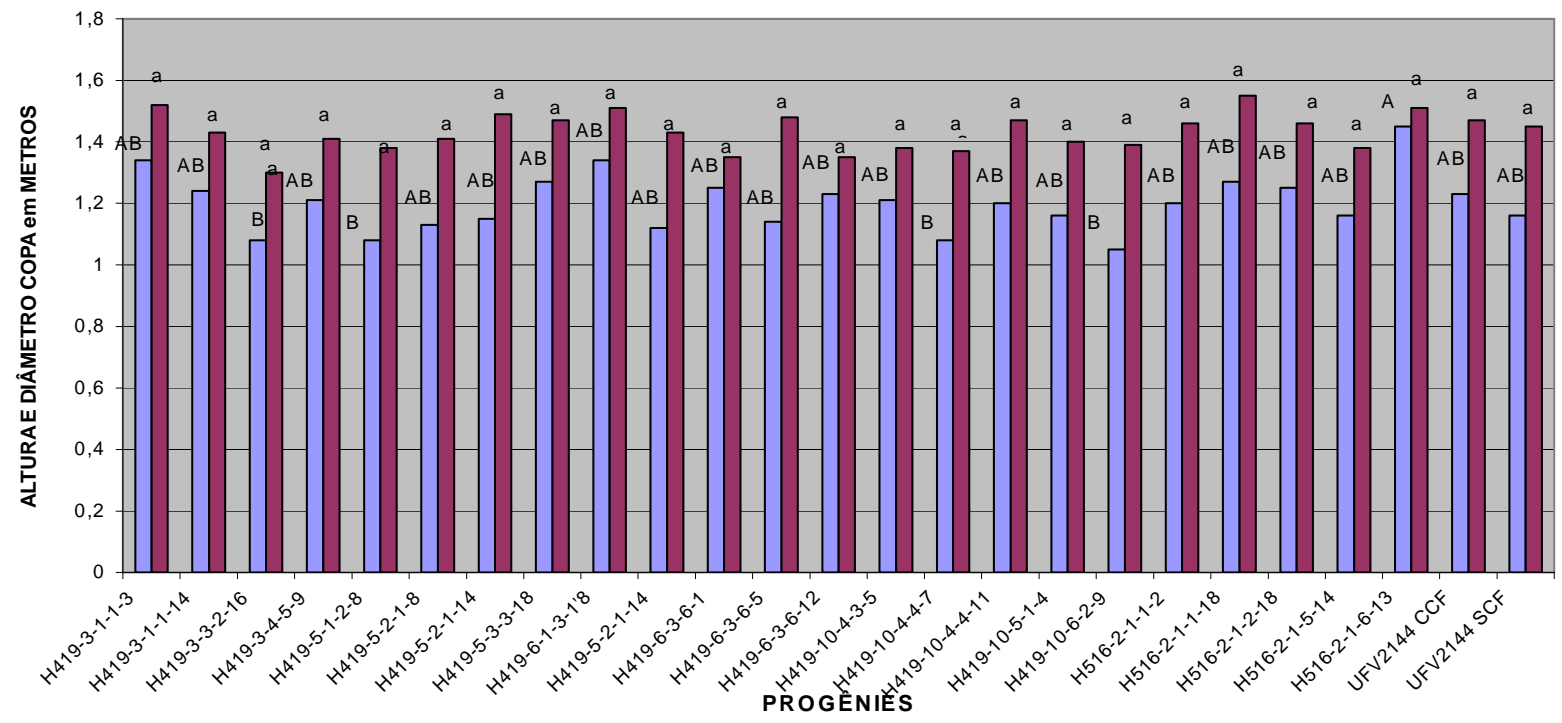

$\mathrm{CV}=8,36 \%$ e 8,19\% DMS $=0,31 \mathrm{~m}$ e 0,37 $\mathrm{m}$ Média Geral $=1,20 \mathrm{~m}$ e 1,43 $\mathrm{m}$-respectivamente

GRÁFICO 1 - Altura e diâmetro de copa das progênies F5 de Catuaí Amarelo com Híbrido de Timor na Fazenda Experimental da EPAMIG de Machado MG, 03/12/2003.

COMPRIMENTO dO RAMO E NÚMERO de INTERNÓDIOS

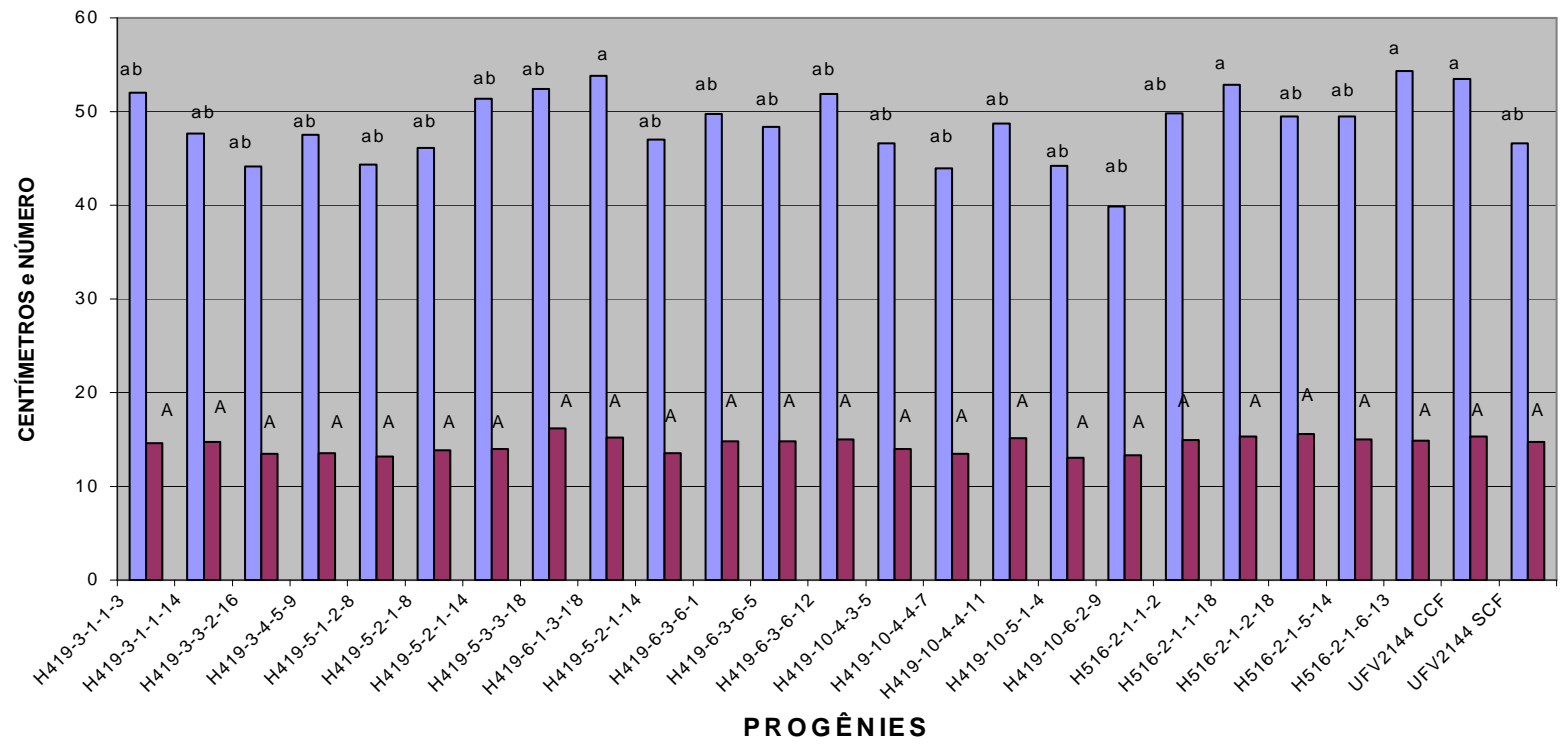

$\mathrm{CV}=8,31 \%$ e 6,80\% DMS =4,04 cm e 0,99 Média Geral =48,69 cm e 14,47 - respectivamente

GRÁFICO 2 - Comprimento do ramo plagiotrópico (em centímetros) e número de internódios das progênies F3 de Catuaí com Híbrido de Timor na Fazenda Experimental da EPAMIG de Machado MG, 03/12/2003.

Ciênc. agrotec., Lavras, v. 29, n. 6, p. 1195-1200, nov./dez., 2005 
PRODUÇÃO QUILOS CAFÉ/PLANTA e ATAQUE FERRUGEM

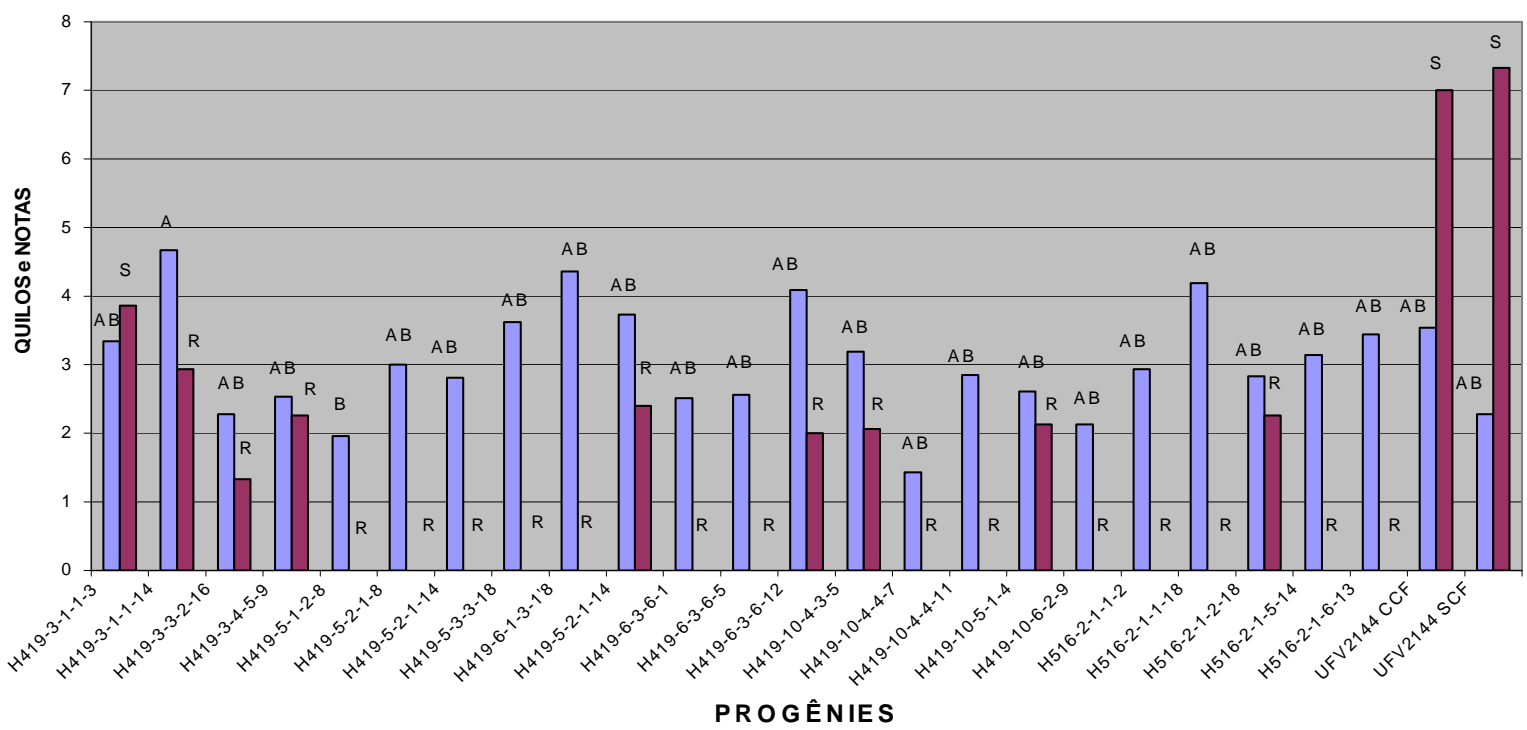

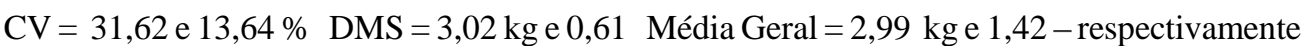

GRÁFICO 3 - Produção em quilos de café cereja por planta relativo os anos 2001, 2002 e 2003 e ataque da ferrugem (notas 1 a 8) das progênies F5 de Catuaí Amarelo com Híbrido de Timor na Fazenda Experimental da EPAMIG de Machado MG, 03/12/2003.

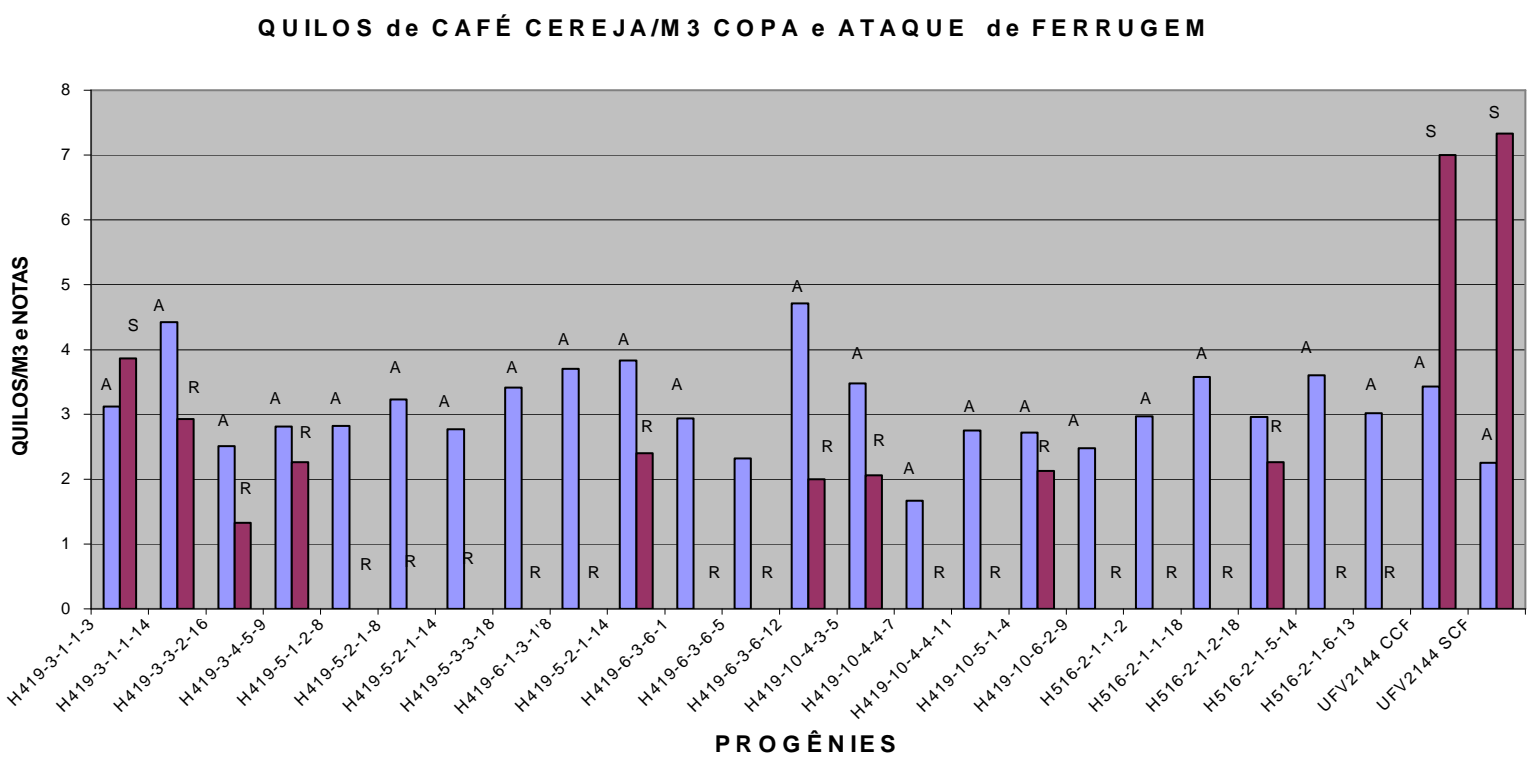

$\mathrm{CV}=34,2$ e $13,6 \%$ DMS $=1,07 \mathrm{~kg} / \mathrm{m} 3$ e 0,61 Média Geral $=2,99 \mathrm{~kg} / \mathrm{m} 3$ e 1,42 - respectivamente

GRÁFICO 4-Produção em quilos de café cereja por $\mathrm{m}^{3}$ de copa nos anos 2001, 2002 e 2003 e ataque da ferrugem (notas 1 a 8) das progênies F3 de Catuaí com Híbrido de Timor na Fazenda Experimental da EPAMIG de Machado MG, 03/12/2003. 
TABELA 1 - Herdabilidades estimada entre médias das progênies F5 de Catuaí Amarelo com o Híbrido de Timor, na Fazenda Experimental da Epamig de Machado MG, 03/12/2003.

\begin{tabular}{lcc}
\hline Atributo Fenotípico & Entre Progênies & Entre e Dentro das progênies \\
\hline Altura das plantas & 0,28 & 0,63 \\
Diâmetro da copa & 0,04 & 0,07 \\
Diâmetro do tronco & 0,11 & 0,36 \\
Comprimento do ramo & 0,18 & 0,53 \\
Número de internódios & 0,11 & 0,39 \\
Resistência à ferrugem & 0,80 & 0,96 \\
Produção kg/planta & 0,16 & 0,54 \\
Produção kg/m3 copa & 0,10 & 0,20 \\
\hline
\end{tabular}

\section{CONCLUSÕES}

Com relação à produção em quilos de café cereja por planta, as progênies F5 de Catuaí Amarelo com o Híbrido de Timor a H419-3-1-1-14 (4,54 kg/planta) e a H516-2-1-1$18(4,21 \mathrm{~kg} / \mathrm{planta})$ foram as mais produtivas, apresentando produtividade superior a variedade Catuaí, podendo ser indicadas para a seleção de progênies destinada a gerações futuras e o cultivo nas condições onde foram realizadas este trabalho. Os atributos vegetativos que mais contribuiram para o aumento dessa produtividade, foram o comprimento dos ramos plagiotrópicos $(\mathrm{r}=0.5977 \mathrm{p}<$ $0.01)$, altura da planta $(\mathrm{r}=0.2848 \mathrm{p}<0.01)$ e o diâmetro do tronco $(\mathrm{r}=0,3316 \mathrm{p}<0.01)$.

Quanto à produção de café cereja por metro cúbico de copa, as progênies F5 de Catuaí Amarelo com o Híbrido de Timor H419-6-3-6-12 (4,70 kg/m3 copa), H419-3-1-1-14 $(4,34 \mathrm{~kg} / \mathrm{m} 3$ copa) e a H419-5-2-1-14 (3,80 kg/m3 copa) foram as mais produtivas. $\mathrm{O}$ atributo vegetativo que mais contribui para o aumento dessa produtividade é o comprimento do ramo, $\mathrm{r}=0.3946 \mathrm{p}<0.01$. Pode-se considerar, para selecionar progênies destinadas a plantios adensados, a produção de café cereja por metro cúbico de copa como um parâmetro confiável, bem como adequar as progênies para os diversos sistemas de cultivo.

Em relação à resistência ao fungo Hemileia vastatrix, as progênies apresentaram herdabilidade no sentido amplo elevado $\left(h_{a}{ }^{2}=0,80\right.$ entre $\quad h_{a}^{2}=0,96$ entre e dentro das progênies), indicando-as com variabilidade genética alta para seleção de material resistente ao ataque do fungo Hemileia vastatrix.

\section{REFERÊNCIAS BIBLIOGRÁFICAS}

CASTILLO-ZAPATA, J.; MORENO-RUIZ, G. Selection de cruzamientos derivados del "Híbrido de Timor" en la obtencion de variedades majoradas de café para Colômbia. Cenicafé, Chinchiná, v. 1, p. 37-53, jan./abr. 1981.

DHALIWAL, T. S. Correlation betwen yield and morphological characters in Puerto Rican and Columnaris varieties of Coffea arabica L. Journal of the Agricultural University of Puerto Rico, Porto Rico, v. 52, p. 29-37, 1968.

PEREIRA, A. A. Herança da resistência a Hemileia vastatrix Berk et Br. em cafeeiros derivados do Híbrido de Timor. 1995. 66 f. Tese (Doutorado) - Universidade Federal de Viçosa, Viçosa, 1995.

SERA, T. Possibilidade de emprego de seleção nas colheitas iniciais de café (Coffea arabica L. cv. Acaia). 1987. 147 f. Tese (Doutorado) - Escola Superior de Agricultura de Luiz de Queiroz, Piracicaba, 1987.

VENCOSVSKY, R.; BARRIGA, P. Genética biométrica no fitomelhoramento. Ribeirão Preto: Sociedade Brasileira de Genética, 1992. 486 p.

VOSSEN, H. A. M. van der. Coffee selection and breeding. In: CLIFFORD, M. N.; WILLSON, K. C. (Eds.). Coffee: botany, biochemistry and population of beans and beverage. Wesport: AVI, 1985. p. 48-96. 